\title{
Microcards and Punched Card Filing
}

\author{
Mr. Rider is librarian, Wesleyan Uni- \\ versity.
}

$\mathrm{A}^{\mathrm{B}}$ BOUT ONCE a month for the last three years the writer has received a letter from someone suggesting what a splendid idea it would be to file microcards by one or another of the punched card sorting techniques. I have had to reply that the filing of microcards, or for that matter the filing of any sort of catalog cards, was not practicable by any of the punched card systems with which I was familiar, and in the case of most of these letters I tried to explain why. Since the volume of this punched-card-filing correspondence is now rather bulky, and since the subject is one that, for obvious reasons, is of considerable practical interest to librarians, it has seemed worth while to put in the record this brief discussion of it.

It must be repeated at the start that this discussion reflects only such mechanical sorting methodologies as are now in use, for around the corner there may be something so new and so different as to make mechanical catalog card filing practicable. By practicable we, of course, do not mean possible, for mechanical card filing is already possible enough. By practicable we mean more efficient.

Proponents of the mechanical filing of catalog cards have failed to realize at its full value the fact that all punched card systems were developed to be, and still are, sorting systems, not filing systems. There is a very real difference between these two words, and in this difference lies the impracticality of punched card techniques for filing. If we are faced with a file of ten million cards, divided up into a thousand or more categories, or combinations of categories, some of them consisting of a few hundred cards only, some of them containing perhaps hundreds of thousands of cards, and we want to segregate from that file any one of these categories it is obvious that we have a sorting job to do, not a filing job. By punching many holes on these ten million cards, or by intricately notching one or more of the edges, in either case according to a predetermined code, we can sort the cards mechanically.

The filing of catalog cards presents an entirely different problem. From a library catalog we never have occasion to sort out, in answer to any patron's request, hundreds of thousands of cards. For one to want even a hundred cards at any one time under any one category (i.e., under any one author or subject heading) is an event of great rarity. Most of the time what one seeks in the catalog is one card-or two or three cards. By using present catalog methods, we may, on the average, take a minute to find that one card that we seek-granted, of course, both a well-made catalog and an intelligent searcher! On the other hand to search that one card out of the catalog mechanically, although it is something that is technically possible, is possible only at a prodigious waste of time and money. Furthermore this waste is one that mounts up in every phase of the mechanical sorting process. Let us analyze it.

First, merely as a preliminary to mechanical searching thereafter, every card that we file in our catalog must be individually 
punched or notched to meet the sorting requirements of our predetermined code. I have no cost figures on this particular phase of punched card technique, but surely this item is in no sense an inconsiderable one. It is strongly to be suspected that it would be considerably more costly than the typing of the catalog card was.

Second, this punching or notching takes up an appreciable proportion of the total space on the card. Notching systems demand for themselves the exclusive use of almost one-half of the total over-all area of the card. Hole-punched systems, can in some cases, be sprinkled over the face of the card without interfering too much with its normal use: but with ordinary catalog cards such an over-all sprinkling would probably be impracticable, and with microcards it would certainly be. In other words, with every catalog card which is intended to be mechanically filed, a definite -and a very substantial-proportion of the total area of the card has to be allocated to notches or punch holes. If this proportion be half of the area then it means that, in the case of microcards, we would have to double the number of cards in our file (which means in turn doubling not only the cost of the microcards themselves but also the cost of the filing equipment and file space rental used by them) simply to effect-we hope-some saving in an important, but still only subsidiary, cataloging cost, i.e. card filing and searching.

We now come to a third question. Is it possible for us to codify, according to any practicable notching or punched hole system, the interminable ramifications and variations of heading which are to be found in any large dictionary catalog? Personally I doubt it.

It is one thing to have a punched hole pattern that will fish out mechanically, from a file of personal name cards, all blue eyed males 65 years old using false teeth-or any other similar combinations of sortings that one may desire to make. But it is quite another thing to have a punched hole sorting pattern that will mechanically fish out for us, out of ten million cards, two entries under the authorship of "Frederick Alexander Stapleton, I822-83."

It is true that permutations do quickly run into astronomical totals. It may be true that a ten million card catalog does not have more than a million different headings. Unfortunately for punched card coding systems, those million headings have a complexity of diversity that stolidly defies any sort of purely numerical transliteration. Most punched card systems deal primarily with surnames. But a full-fledged dictionary catalog requires the mechanical separation not only of surnames, but of full name entries (equipped with birth and death date differentia); and the separation of these from subject headings, some of the latter as many as 12 words long and themselves coupled with numerical and symbolistic differentia, from title entries each several words long, from series entries and other entries. Remember that all of these different forms of entry are now mixed in a single concatenated but minutely differentiated sequence. I would hate to be given the task of plotting a pattern of holes to unravel it.

We have not yet arrived at the fourth phase of our problem, the heart of it, the real nub of punched-card catalog card impracticability. All mechanical sorting systems demand that all the cards involved in a given sorting process be removed from their drawers and run through some kind of a sorting machine. This machine may be the simplest sort of gadget imaginable (in one system a long steel needle suffices to do the trick). Or it may be a very complicated electrical contraption, equipped with all sorts of counting, tabulating, throw out, and cross-checking devices. All these 
devices have, however, as their common denominator the above stated demand for removal. And it is this demand for removal that finally throws out, as impracticable, all mechanical methods of catalog card searching.

Let's take a specific example. You as a reference librarian are asked to ascertain if your library possesses a copy of Pennsylvania Genera of Permian Brachiopoda by one William Selzer. Which process for the answering of this question is the easier one? To do what you do now, i.e. to go to your ten million card catalog and to look in it, under the author entry, "Selzer, William," for a title beginning "Pennsylvania Genera?" Or to resort to a mechanical searching process, which means to take all of your catalog's ten million cards out of their ten thousand catalog drawers and to run them through a mechanical sorting machine (then putting them back into their drawers again) until finally the machine comes to that one "William Selzer" card that you are looking for, and is automatically thrown out for your inspection? The answer is obvious.

Not so obvious at first glance, however, are a host of additional collateral difficulties.
We must remember for one thing that a large library catalog is usually servicing not one card searcher but a dozen-or a hundred-searchers simultaneously. If each one of these hundred searchers is to be mechanically served, it is clear that not one but a hundred sorting machines are going to be required, working simultaneously to find for each patron the single card-or the two or three cards - that each one wants. But for each patron (with ten million cards to be gone through) the automatic searching process is clearly going to be a matter of hours, taking the handling time of dozens of library attendants, and creating an enormous confusion of cards and files simultaneously going through the machine searching routine.

Finally, fifth, what of the physical wear and tear on your cards if they are going to be run constantly through these sorting machines? Obviously this running through is going to involve a certain amount of card erosion.

All of which would seem to sum up to this: that mechanical card filing applied to library card catalogs sounds appealing, but as yet cannot be deemed a practicable proposition.

\section{National Program in Cataloging}

\section{(Continued from page 232)}

for each type of librarianship-school, public and college or university. ${ }^{10}$ Insofar as cataloging is concerned, are there not lessons to be learned from the past? Since Jewett's time have we not got rather far away from the institutional point of view? In the brief account here presented of certain phases of cataloging history, we have learned that the institutional point of view

10 "Southeastern Conference, on Library Education, eastern Library Association, 1948, p. 4. prevailed in the pioneer period of cataloging history, that it steadily lost ground after 1876 , and that since 1908 it has been overwhelmed by a national pattern in card production-a pattern which has been actually detrimental to the welfare of some institutions. In the present renaissance in cataloging history, we hope that the cataloging interests of all types of libraries will find an adequate niche in a sound national program. 